\title{
Very distal transradial approach (VITRO) for coronary interventions
}

\author{
Dominik Wretowski, Marcin Krakowian, Andrzej Łabyk, Piotr Pruszczyk, Marek Roik
}

Department of Internal Medicine and Cardiology with the Centre for Management of Venous Thromboembolic Disease, Medical University of Warsaw, Warsaw, Poland

Adv Interv Cardiol 2019; 15, 1 (55): 42-45

DOI: https://doi.org/10.5114/aic.2019.83771

\begin{abstract}
A bstract
Introduction: Radial access is a standard approach for coronary interventions. However, it carries some risk of local or long-term complications such as hematoma or radial artery occlusion.

Aim: To assess the feasibility of a very distal left and right transradial approach (VITRO) for coronary interventions.

Material and methods: Three hundred and twenty consecutive patients were submitted to diagnostic or therapeutic coronary interventions. In 102 patients the distal radial artery was not palpable or the pulse was too weak. In 218 selected patients (142 male, 76 female, age: $69 \pm 11$ years) we decided to perform a distal transradial approach.

Results: The VITRO access was suitable in 195 patients with a success rate of $89.4 \%$. In 9 patients arterial puncture failed, while in 14 others despite successful arterial puncture the wire could not be advanced towards the forearm part of the radial artery. Not only elective diagnostic angiographies were performed with VITRO but also urgent ad hoc coronary interventions in subjects with unstable angina or NSTEMI (48 subjects; $24.3 \%$ ). Moreover, this very distal approach allowed 11 rotablations and 11 FFR/iFR examinations to be performed in 22 patients. No major bleeding, requiring prolonged hospital stay, surgery or transfusion occurred. One patient on oral anticoagulation with DAPT had conservatively managed minor forearm bleeding.

Conclusions: Very distal radial artery access is feasible, safe and comfortable in $60 \%$ of patients referred for elective or urgent coronary arteries angiography, or coronary interventions.
\end{abstract}

Key words: vascular access, coronary interventions, radial artery, anatomical snuffbox.

Su m m a ry

Significant progress in interventional cardiology made radial access a real alternative to a femoral approach in percutaneous coronary intervention ( $\mathrm{PCl}$ ). However, it carries some risk of local or long-term complications such as hematoma or radial artery occlusion. Recently, more distal radial access has been proposed. This distal transradial access in the anatomical snuffbox was suggested to have some advantages over the standard radial site in terms of better comfort of both patient and operator and potentially decreased the risk of local complications and radial artery related complications. Here, we report our initial experience of the very distal left and right transradial approach (VITRO) for acute stage coronary interventions. To our knowledge this is the first report of such experience in Poland.

\section{Introduction}

There is always constant progress in interventional cardiology. It includes not only new methods such as treatment of structural heart diseases but also more advanced techniques of percutaneous coronary interventions ( $\mathrm{PCI})$. Initially, the femoral approach was used for coronary interventions $(\mathrm{Cl})$. However, currently trans-radial access is strongly preferred [1]. It was proven to be superior to femoral access with significant mortality reduction especially in acute coronary syndromes (ACS) [2]. Moreover, radial access is associated with significantly lower rates of vascular complications including major bleeding [3]. What is important, the radial approach when compared to femoral access provides greater comfort for treated patients [4]. However, it is right radial access which is usually used, and after the intervention

\section{Corresponding author:}

Dominik Wretowski MD, Department of Internal Medicine and Cardiology with the Centre for Management of Venous Thromboembolic Disease, Medical University of Warsaw, 4 Lindleya St, 02-005 Warsaw, Poland, phone: +48 604 968 813, e-mail: wretowski@gmail.com Received: 13.11.2018, accepted: 9.12.2018. 
a transradial compression wristband is applied with compression time up to 120 min. Transradial access carries some risk of local complications. Furthermore, application of the wristband may cause significant patient discomfort and sometimes painful hand swelling. Recently, more distal radial access has been proposed $[5,6]$. This distal transradial access in the anatomical snuffbox was suggested to have some advantages over the standard radial site in terms of better comfort of both patient and operator and potentially lower risk of local complications and radial artery occlusion.

\section{Aim}

The aim of the current study was to assess the feasibility of even more distal transradial access (very distal transradial approach - VITRO) in consecutive patients submitted to diagnostic or therapeutic $\mathrm{Cl}$. The success rate of very distal arterial access, the time from the first puncture to the guidewire insertion and the complication rate were assessed.

\section{Material and methods}

The study included consecutive patients aged over 18 years referred to our catheterization laboratory for diagnostic coronary angiography or for $\mathrm{PCl}$ as the primary procedure in ACS or for elective $\mathrm{Cl}$. We did not include patients with ST elevation myocardial infarction, subjects in cardiogenic shock or patients in whom brachial or ulnar access was preferred, for example patients with forearm dialysis fistulas. All patients signed written informed consent forms. The VITRO study was approved by the Local Ethics Committee (KB 145/2018).

Procedures were performed by four operators experienced in the traditional radial approach. For the current study we used very distal radial access in the area of the anatomic snuff box (VITRO) (Figure 1).

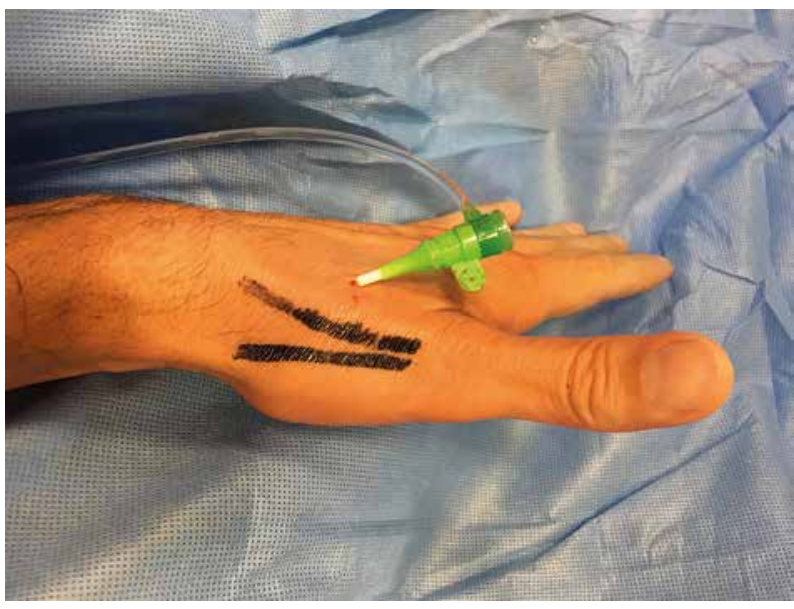

Figure 1. Site of sheath insertions distally from anatomical snuffbox (VITRO accesses)
The selection of left or right arterial access was predominantly based on the presence of a well-palpable distal radial artery and also on the operator's preference.

The left upper limb was placed comfortably on the lower abdomen of the patient while the right forearm was placed as in the traditional radial approach, but without palm supination. After manual localization of the radial pulse laterally to the extensor pollicis longus, de facto in the area of the functional snuff box, arterial puncture was performed. After the localization of a well-palpable radial artery, without ultrasonic guidance and after skin disinfection, local anesthesia (5-10 $\mathrm{ml}$ of $2 \%$ lignocaine) was injected subcutaneously in the area of the snuff box, with a small gauge needle. After 1-2 min the distal radial artery was punctured) with a 21 gauge open needle using a "dancing needle" technique (Figure 2).

Caution was paid to puncture only the anterior atrial wall. Then a vascular 0.018" introducer or 0.014" coronary wire and 7-11 cm $6 \mathrm{Fr}$ introducer sheath were inserted (Prelude, MeritMedical or Radifocus, Terumo). After the insertion of the sheath, the arterial pressure and heart rate were measured. If the patient's systolic BP was above $100 \mathrm{~mm} \mathrm{Hg}, 100-200 \mu \mathrm{g}$ of nitroglycerine and $5000 \mathrm{U}$ of unfractionated heparin were given through the sheath to prevent radial artery thrombosis. Subsequently the procedure was continued in the usual fashion according to its type. We assessed the success rate and the time from the patient's preparation to the first record with a vascular sheath inserted into the radial artery.

After the procedure the sheath was retrieved partially, with a radial hemostatic band placed in a similar way to the traditional approach but more distally, with the pumped pillow adhering to the puncture site. The band covered the thenar area and metacarpus, but not the wrist (Figure 3).

The site of radial artery puncture was subsequently covered with a small aseptic gauze covered with hemo-

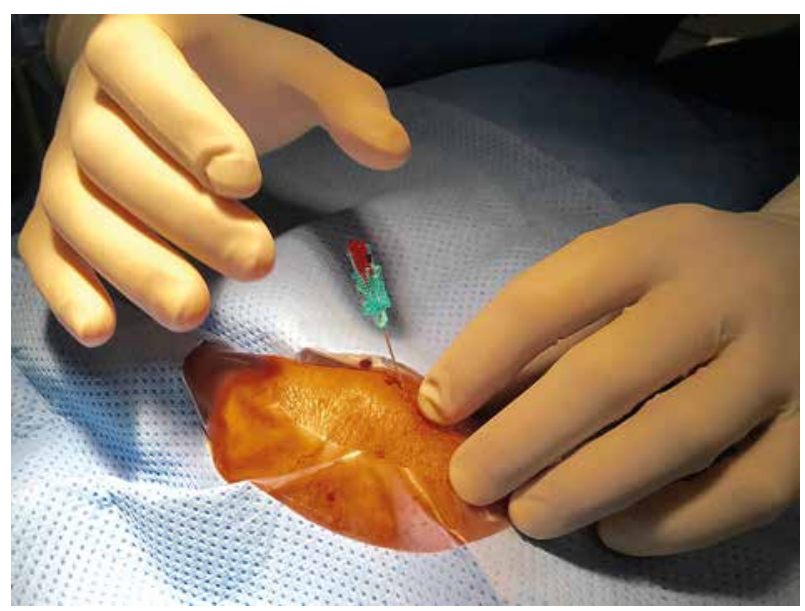

Figure 2. "Dancing needle" - characteristic pulsing of the needle just before puncture of the artery wall 
static band. Prior to discharge from the laboratory, distal radial pulses in the wrist and at the puncture site were assessed.

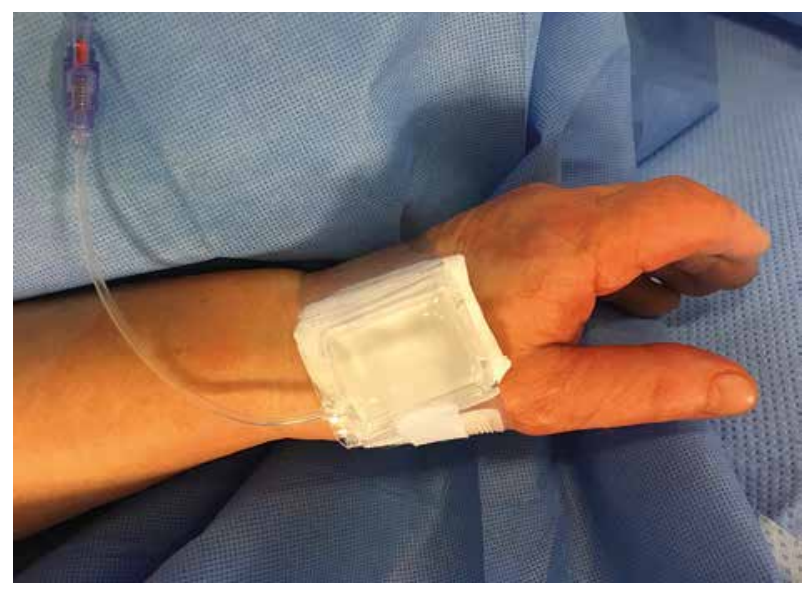

Figure 3. Site of VITRO puncture covered with a hemostatic band (Io TM Radial Artery Compression Tourniquet, COMED B.V.)

Table I. Clinical characteristics of all patients and patients with puncture failure

\begin{tabular}{|c|c|c|}
\hline Parameter & $\begin{array}{c}\text { All } \\
(n=218)\end{array}$ & $\begin{array}{c}\text { Puncture } \\
\text { failure } \\
(n=23)\end{array}$ \\
\hline Age [years] & $68 \pm 11$ & $68 \pm 14$ \\
\hline Male/female & $142 / 76$ & $12 / 11$ \\
\hline Height $[\mathrm{cm}]$ & $1.69 \pm 0.08$ & $1.66 \pm 0.09$ \\
\hline Weight $[\mathrm{kg}]$ & $82.4 \pm 14$ & $76 \pm 13$ \\
\hline Body mass index $\left[\mathrm{kg} / \mathrm{m}^{2}\right]$ & $28.6 \pm 4.8$ & $27 \pm 4$ \\
\hline Hypertension & 175 & 20 \\
\hline Hypercholesterolemia & 140 & 15 \\
\hline $\mathrm{DM} / \mathrm{IFG}$ & 96 & 5 \\
\hline $\mathrm{CHF}$ & 46 & 4 \\
\hline Smoking & 59 & 6 \\
\hline CKD (GFR < 60 ml/min) (dialysis) & $46(18)$ & $5(3)$ \\
\hline OAC & 29 & 5 \\
\hline $\mathrm{OAC}+\mathrm{DAPT}$ & 12 & 1 \\
\hline \multicolumn{3}{|l|}{ Indication for coronary intervention: } \\
\hline Urgent & 53 & 5 \\
\hline Suspected acute coronary syndrome & 10 & 2 \\
\hline UA & 14 & 1 \\
\hline NSTEMI & 19 & 1 \\
\hline Takotsubo & 2 & 0 \\
\hline Myocarditis & 1 & 1 \\
\hline $\mathrm{AHF}$ & 7 & 0 \\
\hline Elective & 165 & 18 \\
\hline
\end{tabular}

AHF - acute heart failure, CHF - congestive heart failure, DAPT - dual antiplatelet therapy, DB - diabetes, GFR - glomerular filtration rate, IFG - impaired fasting glucose, NSTEMI - non-ST-segment elevation myocardial infarction, $O A C$ - oral anticoagulation, UA - unstable angina.

\section{Results}

Between March 2018 and September 2018, 320 patients entered the Vitro program. In 112 (32\%) patients the radial pulse in the snuffbox area was not palpable or was too weak and they were referred for the traditional radial approach. Thus, eventually we included 218 consecutive patients (142 male, 76 female, mean age: 69 \pm 11 years) referred for coronary angiography, elective angioplasty or primary $\mathrm{PCl}$ in ACS. In 165 (75.7\%) patients elective procedures where performed while in 53 (24.3\%) subjects indications for urgent $\mathrm{Cl}$ were present. Detailed patients' characteristics are presented in Table I.

The success rate of the very distal approach was $89.4 \%$ in patients with a palpable radial pulse in the snuffbox area, and $60.1 \%$ of 320 patients who entered the Vitro program. In 9 patients arterial puncture failed, while in 14 others despite successful arterial puncture the wire could not be advanced towards the forearm part of the radial artery. In 32 cases, it was necessary to insert the 0.014 " coronary guidewire due to the resistance when inserting the $0.018 "(0.47 \mathrm{~mm})$ standard guide despite good backflow from the needle. In 28/32 times the use of the coronary guide allowed for the effective assumption of distal access. In 21 failed cases crossover to the traditional radial approach was successfully performed. In two we performed coronary angiography with brachial access and in one case we switched from left distal to right distal access. In all 218 patients $6 \mathrm{Fr}$ sheaths were used. Median procedural time was $6 \mathrm{~min}$, ranging from 2 to $36 \mathrm{~min}$. Detailed information on coronary procedures is listed in Table II.

Not only elective diagnostic angiographies were performed with VITRO but also urgent ad hoc PCl in subjects with unstable angina or non-ST elevation myocardial infarction (NSTEMI). Moreover, this very distal approach

Table II. Procedural characteristics of patients with successful VITRO puncture (145 LdTRA and 51 RdTRA)

\begin{tabular}{lc} 
Parameter & Value \\
\hline Coronary angiography without PCl & 157 \\
\hline Coronary angiography + PCl ad hoc & 36 \\
\hline Elective PCl & 43 \\
\hline $\begin{array}{l}\text { Total number of stents (smallest stent 2.25/30 mm, } \\
\text { largest stent 4.0/30 mm) }\end{array}$ & 102 \\
\hline \begin{tabular}{l} 
Additional procedures: \\
\hline Rotablation
\end{tabular} & 11 \\
\hline FFR/iFR & 11 \\
\hline Introducer: & 111 \\
\hline Prelude 6 Fr & 84 \\
\hline Terumo 6 Fr &
\end{tabular}

FFR - fractional flow reserve, iFR - instantaneous flow reserve, LdTRA - left distal transradial access, $\mathrm{PCl}$ - percutaneous coronary intervention, RdTRA - right distal transradial access. 
allowed us to perform 11 rotablations and fractional flow reserve/instantaneous flow reserve (FFR/iFR) examinations in 11 patients.

Hemostasis and complications. Hemostasis was obtained within two hours in almost all patients. No major bleeding, requiring prolonged hospital stay, surgery or transfusion, occurred. One patient on oral anticoagulation with dual antiplatelet therapy (DAPT) had conservatively managed minor forearm bleeding.

\section{Discussion}

Our experience demonstrates the feasibility of the very distal radial approach located at the functional snuffbox. The vascular approach of this access site was successful in 195 of 218 patients with a well-palpable radial pulse in the snuffbox area with a success rate of $90 \%$ and was similar to the previously reported success rate of the approach in the anatomical snuffbox [7]. However, in an additional 102 of our patients the distal pulse was not palpable or was too weak, and they underwent the traditional radial approach or other (brachial, ulnar). It suggests that in approximately two thirds of consecutive patients referred for coronary angiography the distal radial approach could be performed with a high success rate. It should be underlined that all operators participating in the current study are highly experienced in traditional radial access, and in our laboratory this access is routinely used in more than $98 \%$ of treated patients. We observed no significant learning curve of the very distal radial approach. Median time needed to obtain VITRO was 6 min (time was measured from the patient's preparation to the first (record) loop with a recorded vascular sheath inserted into radial artery). Both left and right distal radial accesses have been reported in the literature $[5,7,8]$. In the current study the choice of site of access was made by the operator according to his and the patient's preferences or possibility (12 of 18 dialysis patients were managed from right access due to fistula on the left forearm). Importantly, in our study the VITRO procedure was not supported by ultrasonographic assessment of the radial artery. Despite this the success rate was similar to the one reported when ultrasonography was incorporated in the protocol [5]. However, it is likely that ultrasound support could be of value in patients with a weak pulse. We used VITRO in both elective and urgent coronary artery angiography and $\mathrm{Cl}$. Interestingly, using this access, it was possible to perform a wide range of interventions, including not only angiography or stent implantations but also FFR and coronary rotablations. We observed no significant complications. Potential advantages of snuffbox access have been reported in previous studies [5, 7-9], and were confirmed in this study. The arm position during the intervention, especially for the left access, was comfortable for the patient and caused no significant palm motor limitations, which is of special value for right-handed patients. A potential important advantage of distal radial access is only $2 \mathrm{~h}$ hemostasis time, because of the superficial position of this small vessel.

\section{Study limitations}

This is a single-center study, and all the procedures were performed by operators highly experienced in radial access. Due to the non-randomized nature of the study and the lack of a control group, conclusions should be made with caution.

\section{Conclusions}

Very distal radial artery access is feasible, safe and comfortable in $60 \%$ of patients referred for elective and urgent coronary artery angiography or coronary interventions.

\section{Conflict of interest}

The authors declare no conflict of interest.

\section{References}

1. Jolly SS, Yusuf S, Cairns J, et al. Radial versus femoral access for coronary angiography and intervention in patients with acute coronary syndromes (RIVAL): a randomised, parallel group, multicentre trial. Lancet 2011; 377: 1409-20.

2. Agostoni P, Biondi-Zoccai GG, de Benedictis ML, et al. Radial versus femoral approach for percutaneous coronary diagnostic and interventional procedures: systematic overview and meta-analysis of randomized trials. J Am Coll Cardiol 2004; 44: 349-56.

3. Jolly SS, Amlani S, Hamon M, et al. Radial versus femoral access for coronary angiography or intervention and the impact on major bleeding and ischemic events: a systematic review and metaanalysis of randomized trials. Am Heart J 2009; 157: 132-40.

4. Valgimigli M, Gagnor A, Calabro P, et al. Radial versus femoral access in patients with acute coronary syndromes undergoing invasive management: a randomised multicentre trial. Lancet 2015; 385: 2465-76.

5. Kiemeneij F. Left distal transradial access in the anatomical snuffbox for coronary angiography (IdTRA) and interventions (IdTRI). Eurolntervention 2017; 13: 851-7.

6. Babunashvili AM, Pancholy SB. Interosseous artery as an access artery in case of late radial artery occlusion. Catheter Cardiovasc Interv 2017; 90: 1121-5.

7. Valsecchi O, Vassileva A, Cereda AF et al. Early clinical experience with right and left distal transradial access in the anatomical snuffbox in 52 consecutive patients. J Invasive Cardiol 2018; 30: 218-23.

8. Soydan E, Akın M. Coronary angiography using the left distal radial approach - an alternative site to conventional radial coronary angiography. Anatol J Cardiol 2018; 19: 243-8.

9. Al-Azizi KM, Lotfi AS. The distal left radial artery access for coronary angiography and intervention: a new era. Cardiovasc Revasc Med 2018; 19: 35-40. 